\title{
PV solar farm as static synchronous compensator for power compensation in hybrid system using Harris Hawks optimizer technique
}

\author{
Kutala Sudarsan ${ }^{1}$, Goturu Sreenivasan ${ }^{2}$ \\ ${ }^{1}$ Department of Electrical and Electronics Engineering, Jawaharlal Nehru Technological University Anantapur (JNTUA), \\ Ananthapuramu, India \\ ${ }^{2}$ PVKK Institute of Technology, Ananthapuramu, India
}

\begin{tabular}{l} 
Article Info \\
\hline Article history: \\
Received May 11, 2021 \\
Revised Jan 28, 2022 \\
Accepted Feb 4, 2022 \\
\hline
\end{tabular}

Keywords:

Chicken swarm optimization

Harris Hawks optimizer

Particle swarm optimization

PV-STATCOM

Tree seed algorithm

\begin{abstract}
Nowadays, the power of impact elements and the proximity and defense areas exist and are increasing exponentially. To alleviate these problems, renew the energy sources such as photovoltaics, wind power, and other things that are made to be taken. This is considered to be a night and night use of static synchronous compensator (STATCOM) to meet the release of load. Solar farm photovoltaic (PV) produces energy during the night and not completely trapped at night. During day, the inverter is used for normal operation and at midnight, it is used to meet load demand more efficiently by controlling voltage, current, active, and reactive power. The proposed strategy is validated in the MATLAB/Simulink software and compared with the existing schemes such as cat swarm optimization-particle swarm optimization (CSO-PSO) and tree seed algorithm (TSA) with recurrent neural network (RNN).
\end{abstract}

This is an open access article under the CC BY-SA license.

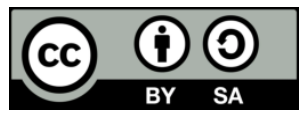

\section{Corresponding Author:}

Kutala Sudarsan

Department of Electrical and Electronics Engineering

Jawaharlal Nehru Technological University Anantapur (JNTUA)

Ananthapuramu, Andhra Pradesh, India

Email: suda.abhi@gmail.com

\section{INTRODUCTION}

Reduced pollution and reliance on nonrenewable resources are important factors in producing large amounts of renewable energy. Ge et al. [1] developed a photovoltaic (PV) model for large solar power for stability studies. Transmission grids often face the challenge of integrating these renewable systems due to their partial energy capacity [2]. Flexible alternating current transmission system (FACTS) devices are being considered to increase the transmission capacity of existing lines [3], [4]. Unlike other forms of energy storage, PV is always associated with an outflow that has a power factor of one, which means that active energy can be used to influence the voltages around the PV at point of common coupling (PCC) by observing the return energy flow in space [5], [6]. In photovoltaic solar farms (SFs), power source converters are critical components that provide solar conversion while the sun is out in full force.Power source converters are critical components of PV SFs, which provide solar conversion during the day (normal operation) [7], [8]. Line loss in the transmission line have been reduced in order to improve transmission capacity and control the flow of energy [9]. Mala et al. [10] explains the impact of static synchronous-strings (SSSC) on the SSIB-controlled SSIB system. The SSSC test results supported by the secondary surveillance radar (SSR) filter are handled by setting the IEEE slacks-based measure (SBM) model [11]. 
Fan and Miao [12] proposes a completely different power management and control system grid connected to the power converter. The study area unit is intended for two kinds ofsingle machine infinite bus (SMIB) programmes. Accurate measurement control is intended to reduce the number of SSR rotor side converters (RSC) required [13].The gate controlled series capacitor (GCSC) has been used for SSR installation. Time analysis is used to evaluate the effectiveness of the GCSC and each thyristor-controlled series compensator (TCSC) in SSR reduction [14], [15]. Distribution static synchronous compensator (D-STATCOM) is used in the distribution system to reduce the amount of compensation required for active energy and harmonics [16]-[18]. An integrated PV matrix with auxiliary moisture control of a solar inverter is used for electrical control; it can act as a transition between day and night to increase temporary stability while simultaneously reducing power transmission costs. The direct current-link (DC-link) voltage of frequently supplied compensation provided according to the compensation requirement using a converted multilevel converter calculator integrated into a PV system.

Devassy and Singh [19] introduced a PV system. The proposed PV system will be transformed into DSTATCOM, which will provide a variety of services such as current sources of compact compression, current load compensation, zero sequence reductions, and maintenance, in addition to serving as an operational capacity during the application phase [20]-[23]. The Harris Hawks optimization (HHO) algorithm is used in this paper for analysis of solar PV-STATCOM during night and day.

\section{STATCOM DESIGN USING HARRIS HAWKS OPTIMIZATIONTECHNIQUE}

When it comes to making the most of the wind system and PV scheme electrical converter, STATCOM is the best option during the day and at night. STATCOM is used for voltage power management as well as damping control. The PV systems generate power to meet the load from the load switching element which is an electric converter that acts as a standard electric converter. It is not a privilege in the dark because the PV system doesn't work. Wind power and STATCOM make up for the lack of the PV system in the night [20]. During those times, the power converter acts like a PV-STATCOM, which controls the amount of power and how it's used.The PV-STATCOM configuration is depicted in Figure 1.



Figure 1. Block diagram for suggested technique

PV-STATCOM, which can act as STATCOM all day, is provided as expected. Power converters from a solar power plant are used as STATCOM operators to provide twenty-four hours of uninterrupted power supply. STATCOM integrates and compensates for a connected system device. As a result, the PV layout is the square measure of the electrical conversion is equal to the standard STATCOM setting. The expected route was analyzed during the day and in the dark. Because of the time of day, the production of PV and wind energy, and the demand for load, the electric converter behaves as if it were a standard electric converter. In the dark state, PV is not available and wind power does not pay for the load demand, that power converter acts as STATCOM compensation and energy management through the use of a generated controller [24], [25]. The two modes of STATCOM operation are described below.

In day time mode, the output power of the PV is sufficient for the need for a reinforcement converter. Meanwhile, it meets the requirement for accountability, but the electric condenser is not connected while in this mode of operation. When operating in nighttime mode, also known as dark operating mode, the PV effect is not caused by solar-powered equipment. The facility is provided by STATCOM through the use of a dark compensation enhancement. 
The HHO is used to control the PV-DSTATCOM switching sequence of the switches and improve system performance [26]. The HHO is a meta-heuristic optimization algorithm, which is established on the mechanism of behavior and chasing style of Harris' Hawks in nature called surprise pounce. The optimization procedure of the HHO technique is presented in Figure 2.

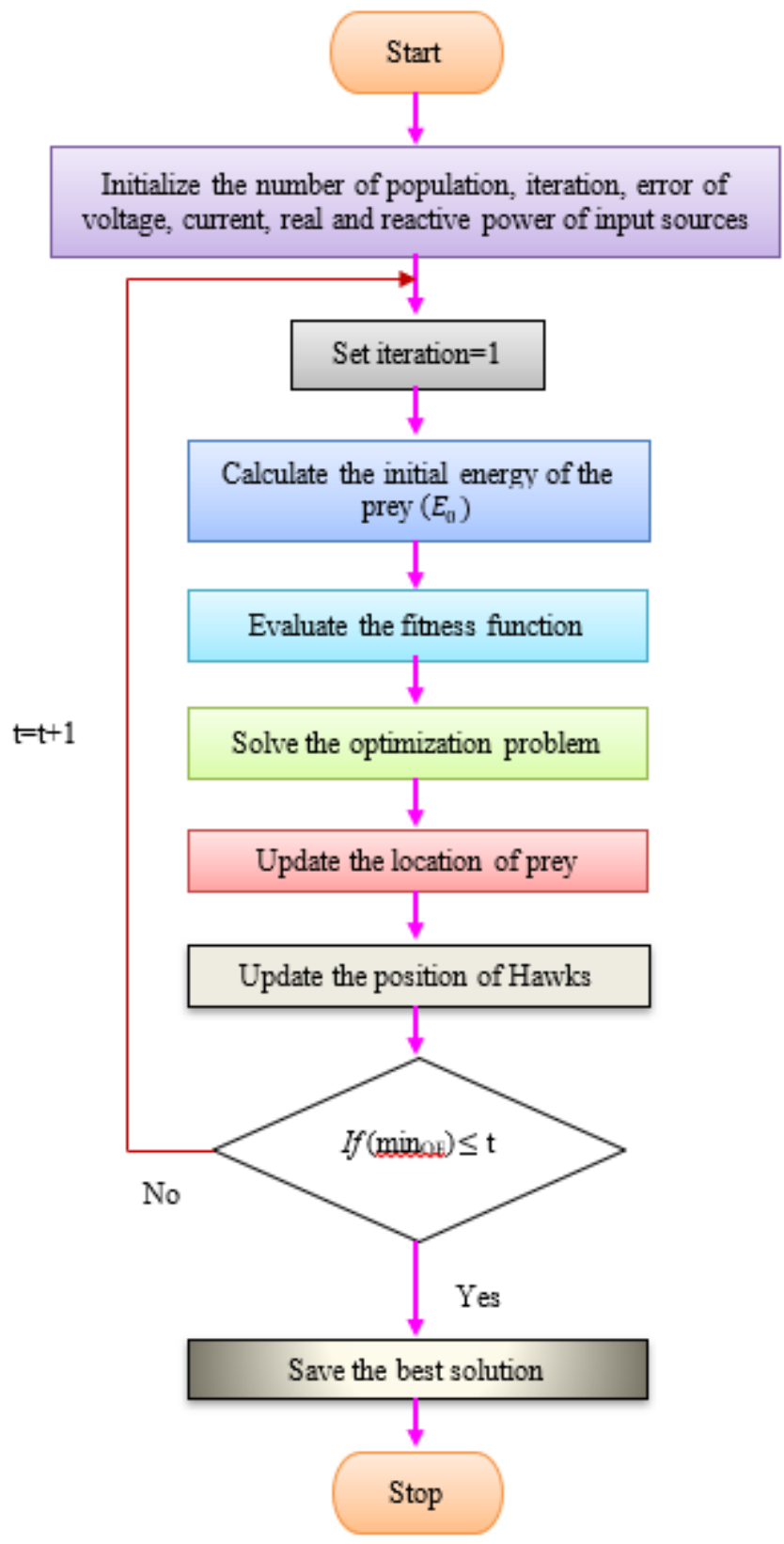

Figure 2. Flowchart of HHO algorithm

\section{RESULTS AND DISCUSSION}

In this section, analyzed the generated controller, which is used to obtain power management, current power, real power, active power, and damping control. Here PV-STATCOM's operational management functionality is enforced within the MATLAB/Simulink platform as shown in Figure 3.The performance of the PV-STATCOM using HHO technique is observed in two modes of operation including day time and night time. 


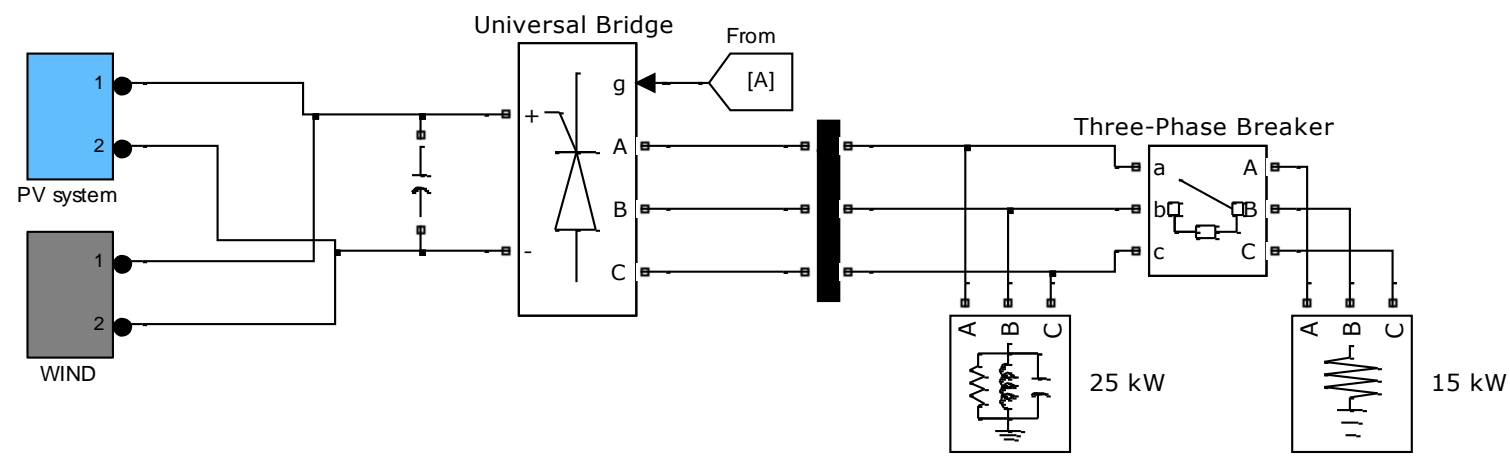

Figure 3. MATLAB/Simulink model used for HHO technique

\subsection{Mode 1: PV-STATCOM during daytime}

The active PV power is high in this mode due to the high level of irradiance. Solar and wind energy is charged based on the time of day for load demand related to the loading and control element. The load requirement varies by completely different seconds of time during this analysis. Figure 4 shows that the load requirement is $8000 \mathrm{~W}$ at this time because the load is different. The condition to be tested should meet the load requirement shown in Figure 5 by using daytime and control analysis. The power generated by PV is different at different interval of times, depends on amount of irradiance as shown in Figure 6.

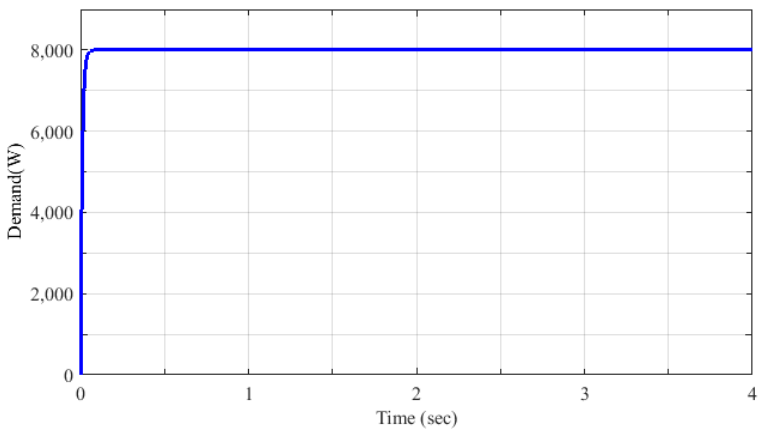

Figure 4. Load demand

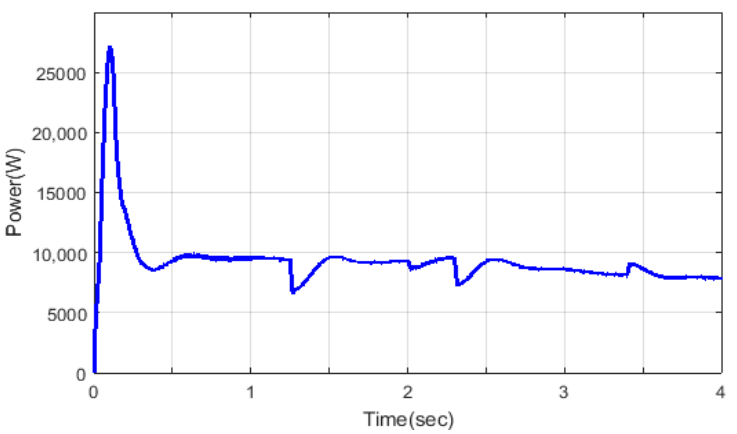

Figure 5. Wind output power

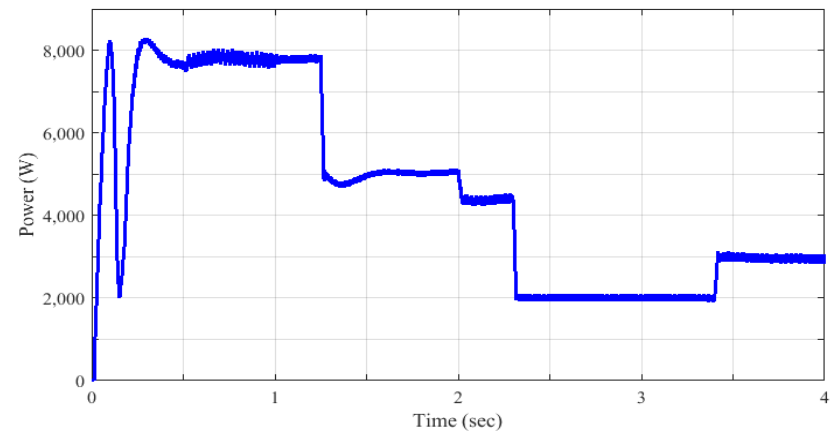

Figure 6. PV output power

Figure 7 (a) shows the variation in demand for the energy produced. The reference power is $8000 \mathrm{~W}$, it defines load demand, and it is written in black. Load demand is met by hybrid system power, which violates the predicted algorithmic system. Similarly, the load varies once in real-time, and thus the power is taken into account. It also tests the output capacity in order to meet the load demand. Figure 7 (b) depicts the best way to meet the burden of needing a variety of systems built by determining the best way to meet the burden of needing a variety of systems built. 




(a)

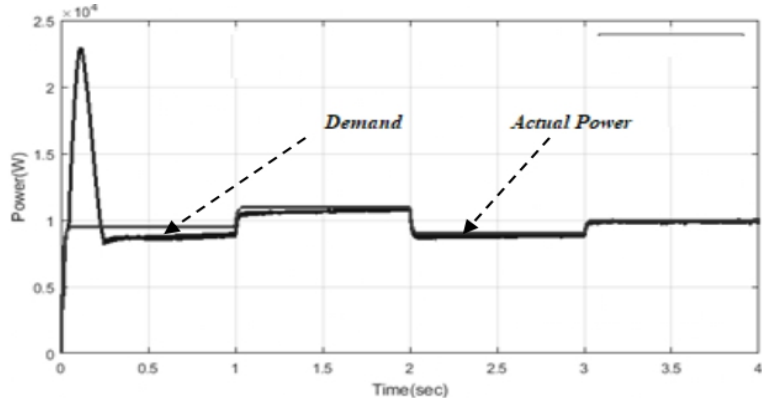

(b)

Figure 7. Response curves (a) comparison with HHO technique and (b) power output with load demand

\subsection{Mode 2: PV-STATCOM during nighttime}

The power to remove the PV range reaches zero in this mode operating system and does not work. While not a PV generation, the load must be forced to meet. What is already dark is mitigation and general management, which is accomplished through the use of the HHO algorithm. During the night, the damping controller uses the entire range of the power converter to generate active controlled power and successfully discharge it. PV power is generated within power; STATCOM already injects the area to meet the load in the dark. During this case study, the demands change at a different rate.

The load requirement in this case was set at $9000 \mathrm{~W}$ at $0-1 \mathrm{~s}, 11000 \mathrm{~W}$ at $1-2 \mathrm{~s}, 9000 \mathrm{~W}$ at $2-3 \mathrm{~s}$, and $10000 \mathrm{~W}$ at 3-4s. PV, a wind power system, is used to pay for the system's load. PV does not produce energy comparisons with daytime analysis in this case. STATCOM injects a zone to protect the material's energy value. This graph depicts an analysis of demand for what is already in the dark. STATCOM and fully generated 10000-11000 W wind power, the demand for responsibility is met within an already existing darkness by utilizing the planned process. To compensate for the center's diversity, STATCOM has been assigned. Figure 8 shows responses with contradictory techniques, demonstrating the strength of a highly structured method. Computation time for various methods is shown in Figure 9. Table 1 shows the performance anaysis of various techniques, from the analysis it is clearly observed that HHO technique gives optimal value with minimum computation time than other techniques.



Figure 8. Output power with demand power

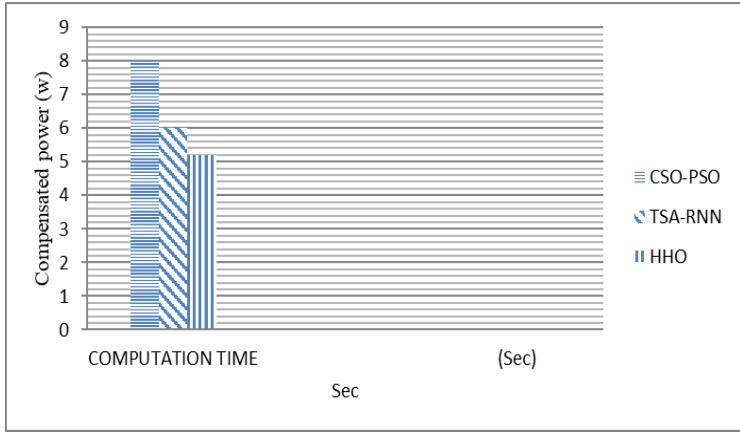

Figure 9. Computation time for various methods

Table 1. Performance analysis of proposed technique

\begin{tabular}{|c|c|c|c|c|c|c|c|c|c|c|}
\hline \multirow{2}{*}{$\begin{array}{l}\text { Mode of } \\
\text { operation }\end{array}$} & \multicolumn{2}{|c|}{ Cases } & \multirow{2}{*}{$\begin{array}{c}\text { Solar } \\
\text { power } \\
(\mathrm{W})\end{array}$} & \multirow{2}{*}{$\begin{array}{c}\text { Wind } \\
\text { power } \\
(\mathrm{W})\end{array}$} & \multirow{2}{*}{$\begin{array}{l}\text { Load } \\
\text { demand } \\
\text { (W) }\end{array}$} & \multicolumn{2}{|c|}{ PV-STATCOM } & \multicolumn{3}{|c|}{ Compensated power(w) } \\
\hline & $\begin{array}{l}\text { Irradiance } \\
\left(\mathrm{w} / \mathrm{m}^{2}\right)\end{array}$ & $\begin{array}{l}\text { Wind } \\
\text { speed } \\
(\mathrm{m} / \mathrm{s})\end{array}$ & & & & $\begin{array}{c}\text { Store } \\
\text { power } \\
(\mathrm{W})\end{array}$ & $\begin{array}{c}\text { Injected } \\
\text { power } \\
(\mathrm{W})\end{array}$ & $\begin{array}{c}\mathrm{HHO} \\
\text { (proposed) }\end{array}$ & $\begin{array}{l}\text { TSA- } \\
\text { RNN }\end{array}$ & $\begin{array}{c}\mathrm{CSO}_{-} \\
\mathrm{PSO}\end{array}$ \\
\hline $\begin{array}{l}\text { Night } \\
\text { time } \\
\text { mode }\end{array}$ & $\begin{array}{c}10-100 \\
w / m^{2}\end{array}$ & $8-10 \mathrm{~m} / \mathrm{s}$ & $\begin{array}{l}100 \mathrm{~W}- \\
2500 \mathrm{~W}\end{array}$ & $5000 \mathrm{~W}$ & $\begin{array}{c}9500 \mathrm{~W}, \\
11000 \mathrm{~W}, \\
9000 \mathrm{~W} \\
1000 \mathrm{~W} \\
\text { at } 0-4 \mathrm{~s}\end{array}$ & - & $\begin{array}{c}\text { Up to } \\
3500 \mathrm{~W}\end{array}$ & 11000 & 10800 & 10500 \\
\hline
\end{tabular}




\section{CONCLUSION}

PV-STATCOM daytime management and pre-dark analysis is presented in this paper. The performance of PV-STATCOM is assessed for load variability between night and day. PV-STATCOM simulation results shows various emissions of PV irradiance, strength, wind speed, and power in all cases. Similarly, a systematic process of imitating wind and PV with power and damping controller is performed and each result is given. The effectiveness of the systematic approach was undeniable by comparative analysis of completely different standard strategies such as CSO-PSO and TSA with RNN. A comparative analysis revealed that the planned management process was more effective than the alternative strategies in improving the performance of the PV-STATCOM system.

\section{REFERENCES}

[1] J. Ge, D. -w. Zhao, J. Ma, Y. -s. Wang, H. -j. Du, and M. -h. Qian, "Wide-area damping controller design of large-scale PV power plants in interconnected power systems," 2016 China International Conference on Electricity Distribution (CICED), 2016, pp. 15, doi: 10.1109/CICED.2016.7576170.

[2] N. K. Singh, M. Z. C. Wanik, A. A. Jabbar, and A. Sanfilippo, "Enhancing PV hosting Capacity of a Qatar Remote Farm Network using Inverters Ability to Regulate Reactive Power-a Case Study," 2019 IEEE PES Innovative Smart Grid Technologies Europe (ISGT-Europe), 2019, pp. 1-5, doi: 10.1109/ISGTEurope.2019.8905545.

[3] K. M. Nathgosavi and P. M. Joshi, "Possibility Study of PV-STATCOM with CHB Multilevel Inverter: A Review," International Conference on Information and Communication Technology for Intelligent Systems, Springer, Singapore, 2020, pp. 579-589, doi: 10.1007/978-981-15-7078-0_56.

[4] L. Wang, X. Liang, and Y. You, "DFIG wind farm modeling for subsynchronous control interaction Analysis," IEEJ Transactions on Electrical and Electronic Engineering, vol. 13, no. 2, pp. 253-261, August 2017, doi: 10.1002/tee.22521.

[5] V. Narasimhulu and K. J. Gowd, "Performance Analysis of Single-Stage PV Connected Three-Phase Grid System Under Steady State and Dynamic Conditions," in Cybernetics, Cognition and Machine Learning Applications, Springer, Singapore, 2021, pp. 39-46, doi: 10.1007/978-981-33-6691-6.

[6] A. M. A. Saif, "Direct Control of D-Statcom Based On 23-Level Cascaded Multilevel Inverter Using Harmonics Elimination Pulse Width Modulation," Masters thesis, Universiti Teknologi Malaysia, Faculty of Engineering-School of Electrical Engineering, 2017, [Online]. Available: http://dms.library.utm.my:8080/vital/access/manager/Repository/vital:132576.

[7] H. V. Padullaparti, S. Jothibasu, S. Santoso, and G. Todeschini, "Increasing Feeder PV Hosting Capacity by Regulating Secondary Circuit Voltages," 2018 IEEE Power \& Energy Society General Meeting (PESGM), 2018, pp. 1-5, doi: 10.1109/PESGM.2018.8586615.

[8] M. J. Masenkane and R. P. Carpanen, "Resonant characteristics of the transmission line compensated with the Static Synchronous Series Compensator," 2017 IEEE AFRICON, 2017, pp. 614-619, doi: 10.1109/AFRCON.2017.8095552.

[9] I. Vieto and J. Sun, "Real-time simulation of subsynchronous resonance in Type-III wind turbines," 2014 IEEE 15th Workshop on Control and Modeling for Power Electronics (COMPEL), 2014, pp. 1-8, doi: 10.1109/COMPEL.2014.6877110.

[10] R. C. Mala, N. Prabhu, and H. V. G. Rao, "Impact of SSSC-ES on Bifurcations of SSR,” Energy Procedia, vol. 117, pp. 559-566, June 2017, doi: 10.1016/j.egypro.2017.05.147.

[11] X. Zheng, J. Zhang, and C. Wang, "Active damping controller design for SSSC to mitigate subsynchronous resonance," IEEE PES General Meeting, 2010, pp. 1-6, doi: 10.1109/PES.2010.5588169.

[12] L. Fan and Z. Miao, "Mitigating SSR Using DFIG-Based Wind Generation," in IEEE Transactions on Sustainable Energy, vol. 3, no. 3, pp. 349-358, July 2012, doi: 10.1109/TSTE.2012.2185962.

[13] A. C. Mahendra, "Novel control of PV solar and wind farm inverters as STATCOM for increasing connectivity of distributed generators," ME Sc. Thesis, Dept. Elect. Comput. Eng., Western Univ., London, ON, Canada, 2013, [Online]. Available: https://ir.lib.uwo.ca/etd/1241.

[14] V. Narasimhulu, D.V.A. Kumar, and Ch. Sai Babu, "Simulation Analysis of Switch Controlled Power Filters for Harmonic Reduction," International Journal of Applied Engineering Research, vol. 11, no. 12, pp. 7597-7602, 2016, doi: 10.37622/IJAER/11.12.2016.7597-7602.

[15] M. Islam, H. A. Mohammadpour, P. Stone, and Y. -J. Shin, "Time-frequency based power quality analysis of variable speed wind turbine generators," IECON 2013-39th Annual Conference of the IEEE Industrial Electronics Society, 2013, pp. 6426-6431, doi: 10.1109/IECON.2013.6700194.

[16] V. Narasimhulu, D.V. A. Kumar, and Ch. S. Babu, "Computational intelligence based control of cascaded H-bridge multilevel inverter for shunt active power filter application," J. Ambient Intell. Human Comput.,2020, pp. 1-9, doi: 10.1007/s12652-01901660-0.

[17] V. Narasimhulu, D. V. A. Kumar, and Ch. S. Babu, "Fuzzy Logic Control of SLMMC-Based SAPF Under Nonlinear Loads," International Journal of Fuzzy Systems, vol. 22, pp. 428-437, 2020, doi: 10.1007/s40815-019-00622-0.

[18] V. Narasimhulu, D. V. A. Kumar, and Ch. S. Babu, "Recital analysis of multilevel cascade H-bridge based active power filter under load variation," SN Appl. Sci., vol. 1, no. 12, p. 1621, 2019, doi: 10.1007/s42452-019-1669-8.

[19] S. Devassy and B. Singh, "Performance Analysis of Solar PV Array and Battery Integrated Unified Power Quality Conditioner for Microgrid Systems," in IEEE Transactions on Industrial Electronics, vol. 68, no. 5, pp. 4027-4035, May 2021, doi: 10.1109/TIE.2020.2984439.

[20] M. Saadatmand, B. Mozafari, G. B. Gharehpetian, and S. Soleymani, "Optimal damping controller design for large-scale PV farms to damp the low-frequency oscillation," International Journal of Renewable Energy Research (IJRER), vol. 9, no. 4, pp. 1672-1680, 2019, doi: 10.20508/ijrer.v9i4.10040.g7769.

[21] A. A. Heidari, S. Mirjalili, H. Faris, I. Aljarah, M. Mafarja, and H. Chen, "Harris hawks'optimization: Algorithm and applications," Future Generation Computer Systems, vol. 97, pp. 849-872, August 2019, doi: 10.1016/j.future.2019.02.028.

[22] M. Mokhtari, S. Zouggar, N. K. M'sirdi, and M. L.Elhafyani, "Voltage regulation of an asynchronous wind turbine using STATCOM and a control strategy based on a combination of single input fuzzy logic regulator and sliding mode controllers," International Journal of Power Electronics and Drive Systems (IJPEDS), vol. 11, no. 3,pp. 1557-1569, September 2020,doi:10.11591/ijpeds.v11.i3.pp1557-1569. 
[23] A. Athamneh and B. Al Majali, "Voltage stability enhancement for large scale squirrel cage induction generator based wind turbine using STATCOM," International Journal of Power Electronics and Drive Systems (IJPEDS), vol. 12, no. 3, pp. 17841794, September 2021, doi: 10.11591/ijpeds.v12.i3.pp1784-1794.

[24] M. S. Alatshan, I. Al Hamrouni, T. Sutikno, and A. Jusoh, "Improvement of the performance of STATCOM in terms of voltage profile using ANN controller," International Journal of Power Electronics and Drive Systems (IJPEDS), vol. 11, no. 4, pp. 19661978, December 2020, doi: 10.11591/ijpeds.v11.i4.pp1966-1978.

[25] N. H. Baharudin et al., "Design and Performance Analysis of Grid Connected Photovoltaic (GCPV) based DSTATCOM for Power Quality Improvements," Journal of Physics: Conference Series, vol. 1878. no. 1, p. 012032,2021, doi:10.1088/1742$6596 / 1878 / 1 / 012032$.

[26] F. Ling et al., "Stability analysis of multiple Static Synchronous Compensators in parallel operation," 2016 IEEE 8th International Power Electronics and Motion Control Conference (IPEMC-ECCE Asia), 2016, pp. 1318-1322, doi: 10.1109/IPEMC.2016.7512480.

\section{BIOGRAPHIES OF AUTHORS}


Kutala Sudarsan (D) SIS SC now pursuing Ph.D. in the Department of EEE In JNTUA University, Anantapur \& also employed as an Assistant Professor, Department of EEE in SRIT Anantapur. His-exploration interests comprise Power systems, Control systems, Electrical Machines \& Renewable energy sources. He is a life member of IE(I). He can be contact at email: suda.abhi@gmail.com.

Goturu Sreenivasan (D) SOS SC employed as a Professor, Department of EEE in PVKK Institute of Technology, Anantapur AP. His-extents of concern comprise Power Systems, Control Systems \& Electrical Machines. He is a life*member of "ISTE\&IE (I). He can be contact at email: gsn.anusree@gmail.com. 